\title{
Clinico-Pathological Study of Juvenile Nasopharyngeal Angiofibroma
}

\author{
Asadur Rahman ${ }^{1, ~ *, ~ K a m r u l ~ H a s a n ~ T a r a f d e r ~}{ }^{2}$, MA Matin ${ }^{3}$, Khorsed Alam ${ }^{1}$ \\ ${ }^{1}$ Department of ENT \& Head-neck Surgery, Shaheed Ziaur Rahman Medical College, Bogura, Bangladesh \\ ${ }^{2}$ Department of ENT \& Head-neck Surgery, Bangabandhu Sheikh Mujib Medical University (BSMMU), Dhaka, Bangladesh \\ ${ }^{3}$ Department of ENT \& Head-neck Surgery, Rajshahi Medical College, Rajshahi, Bangladesh
}

Email address:

dr.asad65@gmail.com (A. Rahman)

${ }^{*}$ Corresponding author

\section{To cite this article:}

Asadur Rahman, Kamrul Hasan Tarafder, MA Matin, Khorsed Alam. Clinico-Pathological Study of Juvenile Nasopharyngeal Angiofibroma. American Journal of Biomedical and Life Sciences. Vol. 8, No. 4, 2020, pp. 91-96. doi: 10.11648/j.ajbls.20200804.15

Received: June 15, 2020; Accepted: July 13, 2020; Published: August 4, 2020

\begin{abstract}
Introduction: Anigo-fibroma is vascular swelling arising in the nasopharynx of prepubertal and adolescent males and exhibiting strong tendency to bleed, also termed as nasopharyngeal fibroma or a nasopharyngeal angiofibroma. It accounts for less than $0.5 \%$ of all head \& neck tumour. It occurs almost exclusively in adolescent male, though rarely found in children and elderly young. It is a rare $<1 \%$ of head and neck tumors benign mesenchymal neoplasm composed of a vascular proliferation within a cellular, densely collagenizedstroma, typically originating in the nasopharynx, affecting adolescent males. It occurs most often in male adolescents with an average age at diagnosis of 14-16 years. Anyway, there are very few studies, regarding Juvenile Nasopharyngeal Angiofibroma in Bangladrsh and there is not much national data about this issue. Hence, the researcher purposively a total of 30 patients of juvenile nasophryngeal angiofibroma (JNA) included in this study from ENT department of Shaheed Ziaur Rahman Medical College, Bogura, Bangladesh. The aim of this study was to find out the common mode of clinical presentation with their site of extension and different surgical approaches adopted for them. Methods\& Materials: This prospective observational study was conducted in the Department of otolaryngology and head, neck surgery of Shaheed Ziaur Rahman Medical College, Bogura, Bangladesh, which is the $2^{\text {nd }}$ generation tertiary level medical service institution during the period from Jan 2017 to Dec 2019. All data were analyzed by using simple statistical data analyzed tools. Result: Almost all the present with recurrent epistaxis 28 (93.33\%), following by nasal obstruction 26 (86.66\%), nasal discharge $25(83.33 \%)$, facial swelling $10(33.33 \%)$, protrusion of the eyeball $4(13.33 \%)$, aural symptoms $3(10 \%)$ and head-ache $2(6.66 \%)$. Majority of our patient presented with multiple symptoms. Analysis of the finding showed that $100 \%$ had nasopharyngeal mass, nasal mass $86.66 \%$ palatal bulging $66.66 \%$, swelling of the cheek $33.33 \%$, proptosis $13.33 \%$ and headache with blurring of vision $6.66 \%$, these are obtained after thorough clinical examination both local and general. Extension of the tumour assessed on the basis $\mathrm{C}$ scan, MRI, as well as observation on the operation showed, nasal cavity $100 \%$ and into the pterygopalantine fossa $40 \%$, infratemporal fossa $33.33 \%$, orbit $13.33 \%$, oropharynx $10 \%$ maxillary antrum $6.66 \%$, sphenoid sinus $3.33 \%$, ethmoidal sinus $3.33 \%$ and $6.66 \%$ infra oranial extension. Regarding treatment surgical resection was the most common principal mode of treatment offered to the $93.33 \%$ patient but radiotherapy given in 6.66\% patient. Conclusion: All young males of this study with nasal obstruction or nose bleed (or both) should be suspected of having juvenile angiofibroma. Angiography to find out feeding vessel to do pre-operative embolization is helpful for surgery. This together with hypotensive anaesthesia and operated by a skilled surgeon having sound knowledge about nasopharynx can lessen the haemorrhage, thereby reduce the mortality and morbidity.
\end{abstract}

Keywords: Clinico-Pathological, Juvenile, Nasopharyngeal, Angiofibroma

\section{Introduction}

Juvenile nasopharyngeal angiofibroma, (JNA) signify itself as extremely vessel related prepubertal/ pubertal benign mesenchymal tumour which arises in the within the tissue of nasopharynx. It not a infrequent tumour and accounts for less than $0.5 \%$ of all head \& neck tumour and $<1 \%$ of benign mesenchymal neoplasm. It occurs almost exclusively in male adolescent with an average age of 14-16 years at diagnosis 
$[2-5,25]$. Children and elderly young of same sex are not immune of this disease. Females are not reported but if suspected, genetic sex must be done to confirm the disease. Histologically it is composed of a vascular proliferation within a cellular collagenized stroma devoid of tunica media coat, which is responsible for torrential bleeding with trivial trauma as muscle coat cannot contract at the first step of hemostasis. [1] Even with the dramatic advancement of medical science, the exact nature of JNA is not yet clear, though the most accepted current view as it is a hemangioma or vascular malformation. Beham et al suggested that angiofibromas were vascular malformations on the basis of the various morphological irregularities they found in the vascular architecture of the tumor. [6] Zhang et al [7] have reported data supporting the theory of JNA being an angiogenic histogenetic tumour and the hallmark of this lesion is uncontrolled vascular endothelial cell proliferation. It behaves, like locally malignant tumour by its highly destructive power, neither it metastasis, nor it infiltrates surrounding tissue but erode vital structure. [8] It has a tendency to recur if not completely removed. [9] However, as the tumour occur at puberty age exclusively in male adolescents and the presence of androgen and estrogen receptors in JNA tissue, a hormone-dependent theory was suggested. But this theory is still disputed as no variation of serum hormonal levels were observed in the patients. $[10,11]$ The site of origin of the tumour is predominantly around pterygopalatine foramen, from where it might spread locally to the nasal cavity, pterygopalatine fossa, infratemporal fossa orbit, or proceed intracranialy. The main presenting symptoms are recurrent nose bleeding, nasal obstruction, swelling in and around the face and or eyes. Beside these nasal speech, headache, insomnia, pansinusitis even blindness also complained. Death due to extension and enlargement within the cranial cavity were reported. [12]. The diagnosis of nasopharyngeal angiofibroma based on the suspicion of clinical features in male sex at puberty age but should always be assisted/ established by special investigations like $\mathrm{x}$-ray, naso-Endoscopy, CT scan, Angiography, MRI \& MRA and confirmed by post-operative histopathological examination. The surgical management of nasopharyngeal angiofibroma with different extra and intracranial extension is very much difficult because of complex anatomy and high risk of morbidity during operation due to torrential hemorrhage. So preoperative judgment, imaging evaluation, selection of appropriate approach is important. These together with skilled surgeons and anesthetics with well-equipped facilities has fallen the risk from previous.

\section{Objectives}

The present study was carried out to observe the:

a) Clinical presentation of nasopharyngeal angiofibroma.

b) Extension of the tumour.

c) Different modalities of treatment offered to them.

\section{Methodology and Materials}

This was a prospective, observational study and was conducted in the Department of otolaryngology and head neck surgery of Shaheed Ziaur Rahman Medical College, Bogura, Bangladesh which is the $2^{\text {nd }}$ generation tertiary level medical service institution during the period from Jan 2017 to Dec 2019. All together 30 patients of juvenile nasopharyngeal angiofibroma (JNA) were included in the study with the age ranging from 7-30 years belong to different socio-economic group. The diagnosis of nasopharyngeal angiofibroma done by from the patient's age, sex, suspected clinical feature and established by routine and special investigation like digital x-ray, nasoendoscopy CT scan, Angiography, MRI \& MRA and confirmed by postoperative histopathological examination. The aim or purpose studies it to find out the common mode of clinical presentation with their site of extension and different surgical approaches adopted for them. The data were analyzed by using simple statistical tools.

\section{Results}

The age range at the time of diagnosis out of 30 patients, the lowest age was 7 years and height age was 30 years, with the average (Median) age of onset being 16 years. In this series of 30 patients, all patients are male. Majority of the patient came from lower socio-economic group and from rural areas $63.33 \%$. No patient from affluent class $0 \%$ as back ground. Almost all the present with recurrent epistaxis $28(93.33 \%)$, following by nasal obstruction $26(86.66 \%)$, nasal discharge $25(83.33 \%)$, facial swelling $10(33.33 \%)$, protrusion of the eyeball 4 (13.33\%), aural symptoms $3(10 \%)$ and head-ache $2(6.66 \%)$. Majority of our patient presented with multiple symptoms. Analysis of the finding showed that $100 \%$ had nasopharyngeal mass, nasal mass $86.66 \%$ palatal bulging $66.66 \%$, swelling of the cheek $33.33 \%$, proptosis $13.33 \%$ and headache with blurring of vision $6.66 \%$, these are obtained after thorough clinical examination both local and general. Extension of the tumour assessed on the basis $\mathrm{C}$. T scan, MRI, as well as observation on the operation showed, nasal cavity $100 \%$ and into the pterygopalantine fossa $40 \%$, infratemporal fossa $33.33 \%$, orbit $13.33 \%$, oropharynx $10 \%$ maxillary antrum $6.66 \%$, sphenoid sinus $3.33 \%$, ethmoidal sinus $3.33 \%$ and $6.66 \%$ infra oranial extension. Regarding treatment surgical resection was the most common principal mode of treatment offered to the $93.33 \%$ patient but radiotherapy given in $6.66 \%$ patient.

Table 1. Presenting symptoms $(n=30)$.

\begin{tabular}{lll}
\hline Symptoms & $\mathbf{N}$ & $\mathbf{\%}$ \\
\hline Recurrent Epictaxis & 28 & $93.33 \%$ \\
Nasal obstruction & 26 & $86.66 \%$ \\
Nasal discharge & 25 & $83.33 \%$ \\
Facial swelling & 10 & $33.33 \%$ \\
Protrusion of the eyeball & 4 & $13.33 \%$ \\
Aural symptoms & 3 & $10 \%$ \\
Head-ache with blurring & 2 & $6.66 \%$ \\
\hline
\end{tabular}


Table 2. Clinical examination findings $(n=30)$.

\begin{tabular}{lll}
\hline Signs & Number & Percentage (\%) \\
\hline Nasopharyngeal mass & 30 & $100 \%$ \\
Nasal Mass & 26 & $86.66 \%$ \\
Palatal Building & 20 & $66.66 \%$ \\
Swelling of the cheek & 10 & $33.33 \%$ \\
Proptosis & 4 & $13.33 \%$ \\
Headache with blurring of vision & 2 & $6.66 \%$ \\
\hline
\end{tabular}

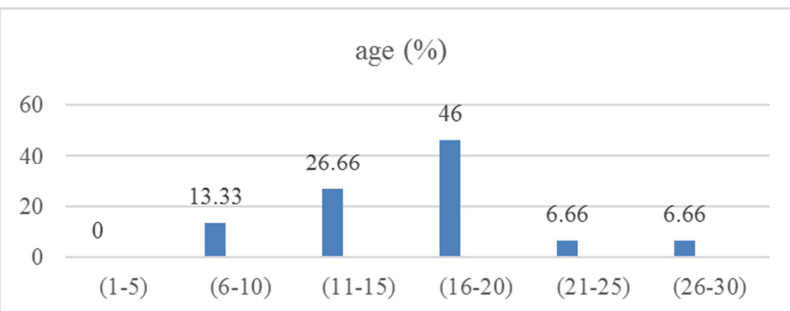

Figure 1. Age distribution $(n=30)$.

Table 3. Extension of the tumour observed during surgery (n-30).

\begin{tabular}{lll}
\hline Site & Number & $\mathbf{( \% )}$ \\
\hline Nasal cavity & 30 & 100 \\
Pterygopalatine fossa & 12 & 40 \\
Infratemporal fossa & 10 & 33.33 \\
Orbit & 4 & 13.33 \\
Oropharynx & 3 & 10 \\
Maxillary antrum & 2 & 6.66 \\
Sphenoid sinus & 1 & 3.33 \\
Ethmoid sinus & 1 & 3.33 \\
Intra oranial extension & 2 & 6.66 \\
\hline
\end{tabular}

Table 4. Nature of treatment given to the patient $(n=30)$.

\begin{tabular}{lll}
\hline Mode of treatment & Number & $\mathbf{( \% )}$ \\
\hline Surgery & 28 & 93.33 \\
Pre-operative radiotherapy & 2 & 6.66 \\
Hormonal therapy & 0 & 0 \\
Pre-operative embolization+surgery & 0 & 0 \\
\hline
\end{tabular}
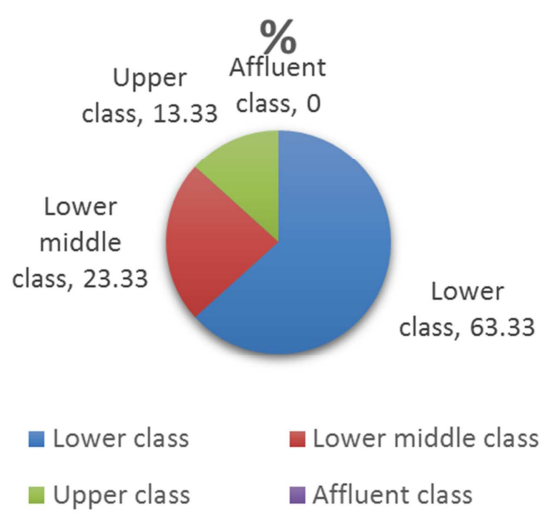

Figure 2. Socio economic condition of the patients $(n=30)$.

Table 5. Total no of patient operated with different approaches $(n=28)$.

\begin{tabular}{lll}
\hline approaches & $\begin{array}{l}\text { No Patient } \\
(\mathbf{n = 2 8 )}\end{array}$ & percentage \\
\hline Transpalatal only & 12 & $40 \%$ \\
Transpalatal with weber fergussion. & 2 & $6.66 \%$ \\
\hline
\end{tabular}

\begin{tabular}{lll}
\hline approaches & $\begin{array}{l}\text { No Patient } \\
(\mathbf{n = 2 8 )}\end{array}$ & percentage \\
\hline Trans palatal with sublabial extension & 3 & $10 \%$ \\
Lateral Rhinotomy only & 4 & $13.33 \%$ \\
Lateral Rhinotomy with transpalatal & 2 & $6.66 \%$ \\
Lateral Rhinotomy and carotid ligation & 2 & $6.66 \%$ \\
Caldwel-luc with Denker modifucation & 2 & $6.66 \%$ \\
Transpalatal \& temporal & 1 & $3.33 \%$ \\
\hline
\end{tabular}

\section{Discussion}

In the study highest number of patient were in the $2^{\text {nd }}$ decades $(73.33 \%)$ which correlate with Dr. R. K Pandey et al. [13] In which it is found in the $2^{\text {nd }}$ decades. The youngest patient was 7 years old and oldest one was 30 years old. In the series all the cases are male which agrees with the Dash et al. [14] series although the disease has been reported in female by Patrocínio JA et al. [15] Socio-economic condition of the patient was poor and middle class which agree with Prusty $\mathrm{N}$ et al. [16, 23] and Gaillard AL et al. [17, 23] series. There is no case reported from affluent class in this series probably they were not attend in this hospital or may seek advice from private clinic or abroad. Commonest symptoms for seeking medical admission of juvenile nasopharyngeal angiofibroma in this series were more than one. Recurrent epistaxis $(93.33 \%)$, nasal obstruction $(86.66 \%)$, nasal discharge $(83.33 \%)$, was the most common combination of symptoms which correlates with the Prusty $\mathrm{N}$ et al. [16] series where recurrent epitaxis (100\%), nasal obstruction (94.4\%) and discharge (88.9\%) were reported. This study agree with Gaillard AL et al [17] series. Analysis of the finding showed that $100 \%$ had nasopharyngeal mass, nasal mass $86.66 \%$ palatal bulging $66.66 \%$, swelling of the cheek $33.33 \%$, orbital extension with proptosis $13.33 \%$ and headache with blurring of vision (intracranial) $6.66 \%$, which correlates with R. K. Pandey et al. [13] and Tiwari PK. [18] In arriving at a diagnosis the common method such as clinical findings and plain digital $\mathrm{x}$-ray of nasopharynx and paranasal sinus were depended upon mainly, since these are by far the cheap and relatively safe method of investigations. Nasoendoscopy and Retrograde endoscopy done in all cooperative patients.

Nasoendoscopy (flexible) and Retrograde nasopharyngoscopy with 90 degree rigid telescope is one of the time honored noninvasive procedure to observe macroscopic appearance of tumour mass with their sites of attachment used in this studies. Reddish mass $(73.33 \%)$ surface covered with smooth mucosa breached at places stained with clotted blood with broad base attachment in posterolateral nasal wall (80\%). Purple mass in the nasopharynx with intact surface $(20 \%)$ where sites of attachment could not identified because of big mass occupying the nasopharynx. Nasoendoscopy shows full of secretion and reddish mass with narrow choana $(86.66 \%)$. Rest were purple big mass in the nasal cavity and scope did not go beyond the mass.

But with the advent and availability of CT scan, angiography, MRI and MRA, it become easier to detected extension of the tumour in different site prior to surgery. 
Different staging of the tumour was done by Session and Paris J. et al. [20] on the basis of CT scan and MRI. Almost all patient in this series were did digital x-rays and CT scan with MRI in $8(26.66 \%)$ cases. Digital subtraction Angiography (DSA) done in $16.66 \%$ cases where internal maxillary artery is the feeding vessel identified. In this study majority $(86.6 \%)$ had their extension into the nasal cavity later encroaching up to the pterygopalatine fossa (positive antral sign) $40 \%$ which correlates with Mistry RC et al. [22], infra temporal fossa $33.33 \%$, which agree with Tang IP1 et al., Alauddin $\mathrm{M}$ et al. and Wanpeng Li et al. [21, 24, 25]. Where it is about $35 \%$ and orbit $13.33 \%$, Maxillary antrum $3.33 \%$ which are not agree with Terzian AE et al. [20] where it is about $12 \%$ but ethmoid sinus $3.33 \%$ which coincide with Prusty N et al. [16] and Paris J. et al. [19]. Regarding intracranial extension, $6.6 \%$ cases shows intracranial extension which correlate with Gaillard AL et al. [17] where it is about $8-10 \%$ and Paris J. et al. [19] but disagree with P. $\mathrm{K}$ Pandey et al. [13] series where it is about $30 \%$. Treatment which offered to the patient mainly were surgery. 2 patient $(6.66 \%)$ in this series were given pre-operative radiotherapy to reduce the vascularity before surgery, because of intracranial extension. Patient were discharged and referred to the skull base surgeon in neurosurgery department. But thereafter these patients didn't come back within three years of this study. So their fate is not known. Reminder of the patient was undergone surgery by different surgical approach. Transpalatal approach 12 (40\%) was preferred in majority of cases as surgeon's familiarity, experience with tumour extension. Not only has that it also given wide exposure to the nasopharynx as well as access to those mass involving the sphenoid sinus and posterior part of the nasal cavity. In addition, this incision can easily be extended when the tumour invaded into the pterygopalatine and infra temporal fosse. Though complete removal is very difficult because of tough fibrotic tumour mass in complex anatomical sites, even then this is good approach because when tumour has invaded neighboring region, it has not only paved the way for its invasion, but also created a pathway for its surgical removal. On the other hand, it is believed that transpalatal approach was not practical for any tumour larger than $10 \mathrm{~cm}$. Lateral rhinology is the $2^{\text {nd }}$ common surgical approach $4(13.33 \%)$. However starting with either transpalatal or lateral Rhinotomy and later on combined with other approach given table 5. Endoscopic embolization not done in this series because of lack of set up facilities. External carotid artery ligation done in 2 cases.

In this study, most of the histo- pathological report showed small cellular collagenized stroma with predominant vascular component with endothelial proliferation and devoid of tunica media coat $22(73.33 \%)$ out of 30 . That is the reasons for torrential hemorrhage after trivial trauma as vessel cannot contract as the first steps of hemostasis. On the other hand 08 $(26.66 \%)$ out of 30 shows strong cellular colllageanted stroma with less vascular component known as fibroangioma.

Limitations of the Study

Our study was not a blinded study so patient bias was present along with observer bias in subjective recording and the small sample size, lack of deal with patients. So the findings of this study may not reflect the exact scenario of the whole country.

\section{Conclusion and Recommendations}

Nasopharynx is a clinically blind space. It is difficult to see or feel. Juvenile Nasopharyngeal Angiofibroma (JNA) may confused with infected antro-choanal polyp with young males with nasal obstruction. However, nasal obstruction with history of recurrent nose bleeding (or both) should be suspected of having juvenile angiofibroma. This awareness as well as a good physical examination and evaluation is essential. Plain roentnogram of the sinus with submentovertical views, CT scan, Angiography and MRI are sufficient adjuncts for diagnosis. Through imaging Knowledge of the point of tumor, origin with their extension into posterior nasal cavity, nasopharynx, sphenoid sinus, pterygomaxillary and infra temporal fossae and canial cavity is essential in staging and planning of treatment. Angiography to identify the feeding vessel to do pre-operative embolization is helpful for surgery This together with hypotensive anaesthesia treated by a skilled surgeon who has sound knowledge about nasopharynx can reduce this type of mortality and morbidity by lessening the hemorrhage. Thereby, it also helps to remove tumour in entity.

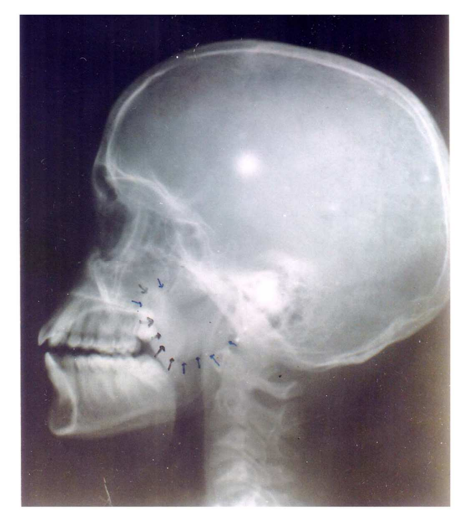

Figure 3. X-ray soft tissue nasopharynx showing nasopharynageal angiofibromatous mass in young adolescent male.

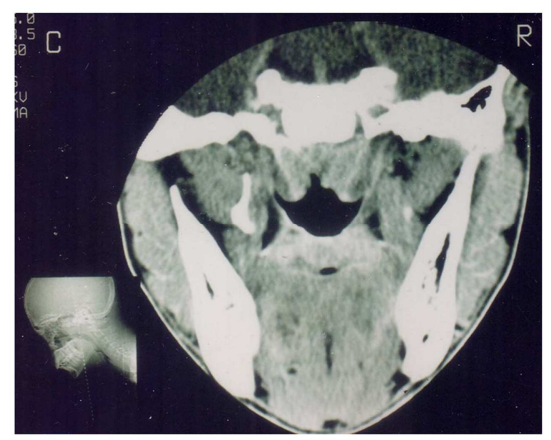

Figure 4. CT Scan of a patient having JNA with involvement into the sphenoid sinus and infratemporal fossae. 


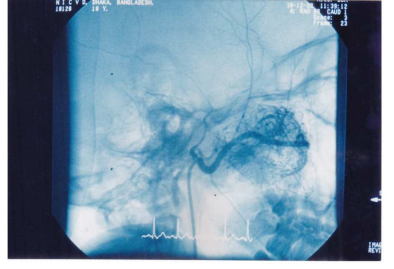

Figure 5. Angiogram showing feeding vessel (Internal maxillary artery) with tumour blush.

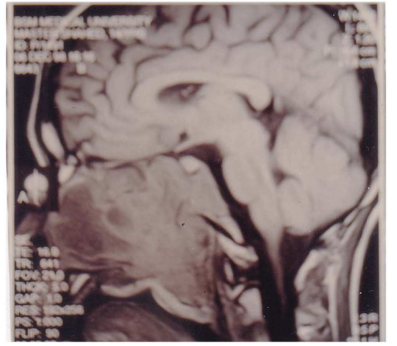

Figure 6. MRI in sagital section showing huge nasopharyngeal mass extended into the pterygopalatine fossae and infratemporal fossae.

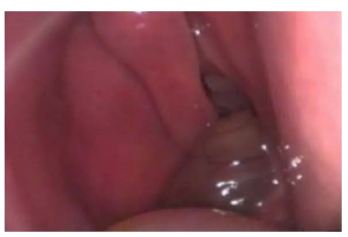

Figure 7. Naso-Endoscopic view of JNA mass with prominent vessel over it.

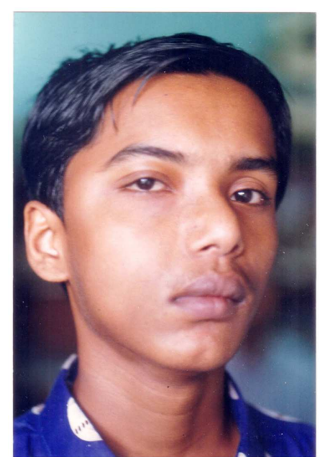

Figure 8. Photograph of patient at recurrent JNA showing right sided facial \& temporal swelling.

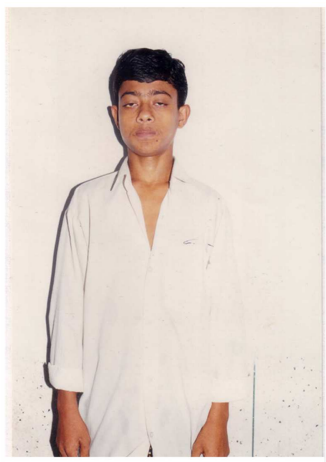

Figure 9. An young male having Nasopharyngeal mass with extension into the orbit causing proptosis.

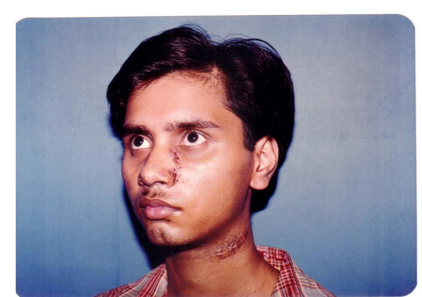

Figure 10. An young male showing external carotid artery ligation with lateral rhinotomy incision.

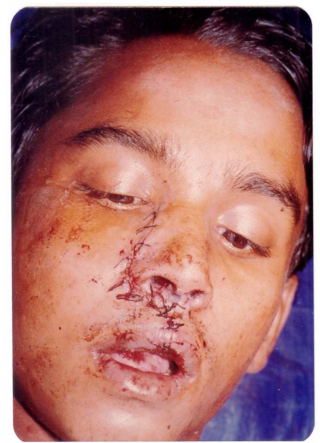

Figure 11. Photograph of a patient having JNA showing lateral rhinotomy incision for removal of mass.

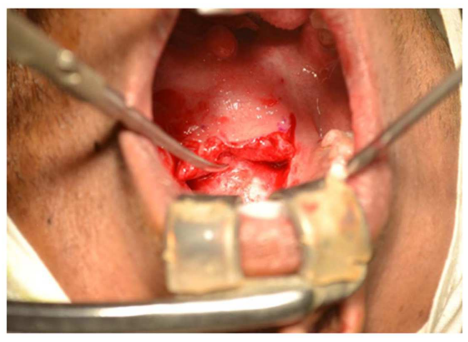

Figure 12. Transpalatal incision for removal of tumour mass.

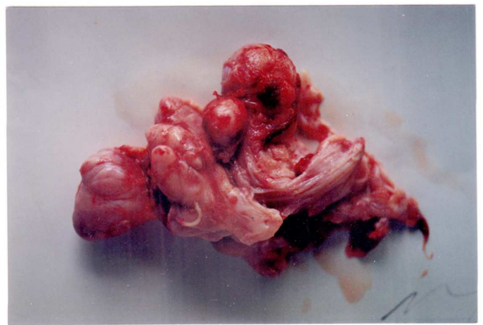

Figure 13. Macroscopic appearance of resected mass.

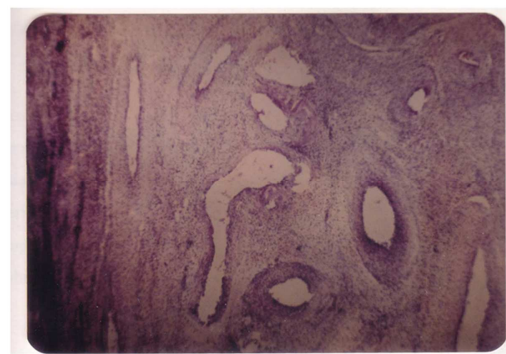

Figure 14. Histopathological picture of nasopharyngeal angiofibroma showing blood vessel devoid of tunica media layer with fibrous tissue elements (10 times magnification). 


\section{References}

[1] Prasad ML, Franchi A, Thompson LDR. Tumours of the nasopharynx: soft tissue tumours: nasopharyngeal angiofibroma. In: El-Naggar AK, Chan JKC, Grandis JR, Takata T., Slootweg PJ, editors. World health organization classification of head and neck tumours. 4. Lyon, France: IARC Press; 2017. pp. 74-75.

[2] Rekonnen S., Hagstrom J., Vuola J., The changing surgical management of juvenile nasopharyngeal angiofibroma. Eur Arch Otorhinolaryngol 2011; 268: 599-607.

[3] Hyun DW, Ryu JH, Kim YS. Treatment outcomes of juvenile nasopharyngeal angiofibroma according to surgical approach. Int J. PedOtorhinolaryngol 2011; 75: 69-73.

[4] Roche PH, Paris J, Regis J, Management of invasive juvenilena sopharyngealangi of ibromas: therole of multimodality approach, Neuro surgery 2007; 61: 768-777.

[5] Beham A, Beham-Schmid C, Regauer S, Nasopharyngealangiofibroma: true neoplasm or vascular malformation? AdvAnat Pathol 2000; 7: 36-46.

[6] LiangJ, Yi Z, Lianq P. Then ature of juvenilena sopharyngealangi of ibroma. Otolaryngol Head NeckSurg 2000; 123: 475-481.

[7] Zhang M., Sun X., Yu H., Biological distinctions between juvenile nasopharyngeal angiofibroma and vascular malformation: an immunohistochemical study. Acta Histochemica 2011; 113: 626-630.

[8] Chandler RJ Gaulding R., Nasopharyngeal angiofibroma staging and management. Annals of otology. Rhinology and laryngology 1984; 93: 322-329.

[9] Wilson WR, Miller D., Lee KJ, yules RB, Juvenile nasopharyngeal angiofibroma, Larygoscope 1972; 82: 985.

[10] Farag MM, Ghanimah SE, Ragaie A, Hormonal receptors in juvenile nasopharyngeal angiofibroma. Laryngoscope 1987; 97: 208-211.

[11] Saylam G., Yucel OT, Sungur A., Proliferation, angiogenesis and hormonal markers in juvenile nasopharyngeal angiofibroma. Int J. Pediatr Otorhinolaryngol 2006; 70: 227 234 .

[12] Yi Z., Fang Z., Lin G., Lin C., Xiao W., Li Z., et al. Nasopharyngeal angiofibroma: A. concise classification system and appropriate treatment options. Am J. Otolaryngol. 2013; 34: 133-41.
[13] Dr. R. K. Pandey et al, A. Comparative Study of Juvenile Nasal Angiofobroma with other Nasal Masses, IOSR, Journal of Medicine, 2017, pp 32-34.

[14] Rajat Kumar Dash et al, Juvenile Nasopharyngeal Angiofibroma, Annals of International Medical \& Dental Research, 2017, vol (4), pp: 2395-2814.

[15] Patrocínio JA, Patrocínio LG, Borba BHC, Bonatti BS, Guimarães AHB. Nasopharyngeal angiofibroma in na elderly woman. Am J Otolaryngology. 2005; 26: 198-200.

[16] Prusty N., Guru RK, Pradhan DK. A. retrospective study on the occurrence and presentation of juvenile nasopharyngeal angiofibroma. Int J Current Res. 2014; 6 (1): 4627-4628.

[17] Gaillard AL, Anastácio VM, Piatto VB, Maniglia JV, Molina, FD. A. seven-year experience with patients with juvenile nasopharyngeal angiofibroma. Braz. J Otorhinolaryngol. 2010; 76 (2): 245-50.

[18] Tiwari PK, Teron P., Saikia N., Saikia HP, Bhuyan UT, Das D. Juvenile Nasopharyngeal Angiofibroma: A Rise in Incidence Indian J. Otolaryngol Head Neck Surg. 2016; 68 (2): 141-148.

[19] Paris J., Guelfucci B., Moulin G., Zanaret M., Triglia JM. Diagnosis and treatment of juvenile nasopharyngeal angiofibroma. Eur Arch Otorhinolaryngol 2001; 258: 120-124.

[20] Terzian AE. Juvenile Nasopharyngeal Angiofibroma Transantral Microsurgical Approach. A. C. Stamm et al. (eds.), Micro-endoscopic Surgery of the Paranasal Sinuses and the Skull Base@ Springer-Verlag Berlin Heidelberg 2000.

[21] I P Tang, S Shashinder, G Gopala Krishnan, P Narayanan. Juvenile nasopharyngeal angiofibroma in a tertiary centre: tenyear experience. Singapore Med J. 2009; 50 (3): 261-4.

[22] Mistry RC, Qureshi SS, Gupta S, Gupta S. Juvenile nasopharyngeal angiofibroma: A. single institution study. Indian J Cancer. 2005; 42: 35-9.

[23] Amin MN, Bhattacharjee N, Juvenile Nasopharyngeal Angiofibroma. Reviwe of 82 cases, journal of college of physician and surgeons 1990; 7: 15-22.

[24] Alauddin M, Abdullah M, Ahmed K. Juvenile Nasopharyngeal Angiofibroma. A. Reviwe of 135 cases, journal of college of physician and surgeons 1995; 13: 90-94.

[25] Wanpeng Li, Yang Ni, Hanyu Lu, Li Hu, Dehui Wang, Current Perspectives on the Origin Theory of Juvenile Nasopharyngeal Angiofibroma, Discov Med j, 2019; 27 (150): 245-254. 